\title{
Perspective on Diagnostic Criteria for Obesity and Abdominal Obesity in Korean Adults
}

\author{
Ga Eun Nam ${ }^{1}$, Hye Soon Park ${ }^{2, *}$ \\ ${ }^{1}$ Department of Family Medicine, Sahmyook Medical Center, Seoul, ${ }^{2}$ Department of Family Medicine, Asan Medical Center, University of Ulsan College of Medicine, \\ Seoul, Korea
}

Excessive body weight is associated with increased health risks in humans. In general, the risk of mortality increases with greater obesity. The 2018 guideline for the management of obesity by the Korean Society for the Study of Obesity proposed the body mass index (BMI) cut-off levels of $25 \mathrm{~kg} / \mathrm{m}^{2}$ and $23 \mathrm{~kg} / \mathrm{m}^{2}$ as diagnostic criteria for obesity and overweight (pre-obese) in Korean adults, respectively. Abdominal obesity has been defined as waist circumference (WC) $\geq 90 \mathrm{~cm}$ in men and WC $\geq 85 \mathrm{~cm}$ in women. In this review, the validity of these criteria for Korean adults was examined based on the evidence regarding the associations of obesity index with mortality and morbidity. The American Association of Clinical Endocrinologists/American College of Endocrinology algorithm and American Diabetes Association guideline for the medical care of obese and overweight patients support a BMl of $25 \mathrm{~kg} / \mathrm{m}^{2}$ and $23 \mathrm{~kg} / \mathrm{m}^{2}$, respectively, as the cut-off levels for Asians (and some ethnicities) corresponding to the BMI values of $30 \mathrm{~kg} / \mathrm{m}^{2}$ and $25 \mathrm{~kg} / \mathrm{m}^{2}$, respectively, for Caucasians. In the future, the optimal cut-off levels for obesity and abdominal obesity may require adjustment as the demographic characteristics of the Korean population change. In addition, development of more valid indicators that better reflect health risks of obesity is needed.

Key words: Obesity, Abdominal obesity, Criteria, Body mass index, Waist circumference, Korean adults

Received July 27, 2018

Reviewed August 10, 2018

Accepted August 19, 2018

${ }^{*}$ Corresponding author

Hye Soon Park

(i)

https://orcid.org/0000-0002-9514-2401

Department of Family Medicine, Asan Medical Center, University of Ulsan College of Medicine, 88 Olympic-ro 43-gil, Songpa-gu, Seoul 05505, Korea Tel: +82-2-3010-3813

Fax: +82-2-3010-3815

E-mail: hyesoon@amc.seoul.kr

\section{INTRODUCTION}

The World Health Organization announced the seriousness of obesity in the near future on their obesity fact sheet in $2017 .{ }^{1}$ Obesity has nearly tripled since 1975 and more than 1.9 billion adults (39\%) were overweight and over 650 million (13\%) were obese worldwide in 2016. Based on several health reports, obesity is expected to become the top leading cause of death in people, surpassing smoking. ${ }^{2}$

According to the data from the Organization for Economic Cooperation and Development (OECD) in 2017, the prevalence of obesity defined by body mass index $(\mathrm{BMI}) \geq 30 \mathrm{~kg} / \mathrm{m}^{2}$ among individuals older than 15 years was the highest in the United States at $38.2 \%$, the lowest in Japan at 3.7\%, and the second lowest in Korea at $5.3 \%{ }^{3}$ Consequently, the same criteria are used to compare the prevalence of obesity among different populations. One reason for the classification of obesity index is to compare weight status within or between populations. ${ }^{4}$ Consequently, a BMI of $30 \mathrm{~kg} / \mathrm{m}^{2}$ has been adopted as the cut-off level for obesity criteria worldwide. ${ }^{3}$ However, in Asia including Korea, a BMI of $25 \mathrm{~kg} / \mathrm{m}^{2}$ was determined as the cut-off level for the diagnosis of obesity as well as other issues including identification of individuals and groups at increased risk of morbidity and mortality, to provide intervention priorities at individual and community levels, and for evaluation of interventions in that population. ${ }^{4}$

According to the 2018 guideline for the management of obesity by the Korean Society for the Study of Obesity (KSSO), the cutoff levels for the diagnosis of obesity and overweight were defined

Copyright (C) 2018 Korean Society for the Study of Obesity

(a) This is an Open Access article distributed under the terms of the Creative Commons Attribution Non-Commercial License (http://creativecommons.org/licenses/by-nc/4.o/) which permits unrestricted non-commercial use, distribution, and reproduction in any medium, provided the original work is properly cited. 
Table 1. Classification of BMl levels and risk of comorbidities based on BMI and WC values using data analysis of a large, nationally representative cohort of Korean adults $^{5}$

\begin{tabular}{lccc}
\hline & & \multicolumn{2}{c}{ Risk of comorbidity } \\
\cline { 3 - 4 } Classification* & $\mathrm{BMI}\left(\mathrm{kg} / \mathrm{m}^{2}\right)$ & $\begin{array}{c}\text { WC }<90 \mathrm{~cm} \text { in men } \\
<85 \mathrm{~cm} \text { in women }\end{array}$ & $\begin{array}{c}\text { WC } \geq 90 \mathrm{~cm} \text { in men } \\
\geq 85 \mathrm{~cm} \text { in women }\end{array}$ \\
\hline Underweight & $<18.5$ & Low & Moderate \\
Normal & $18.5-22.9$ & Moderate & Slightly high \\
Pre-obese & $23-24.9$ & Slightly high & High \\
Class I obesity & $25-29.9$ & High & Very high \\
Class II obesity & $30-34.9$ & Very high & Highest \\
Class III obesity & $\geq 35$ & Highest & Highest \\
\hline
\end{tabular}

*Pre-obese can be referred to as overweight and class III obesity as severe obesity. $\mathrm{BMI}$, body mass index; WC, waist circumference.

as BMIs of $25 \mathrm{~kg} / \mathrm{m}^{2}$ and $23 \mathrm{~kg} / \mathrm{m}^{2}$, respectively. Abdominal obesity has been defined as waist circumference (WC) $\geq 90 \mathrm{~cm}$ in men and $\geq 85 \mathrm{~cm}$ in women (Table 1). ${ }^{5}$ In this review, the validity of these criteria for Korean adults was examined based on the data regarding the relationship between obesity index and mortality and morbidity.

\section{DATA BASED ON THE RELATIONSHIP BETWEEN BMI AND MORTALITY}

\section{Various results regarding the relationship between BMI and mortality}

Numerous studies regarding the relationship between BMI and mortality have been conducted since the mid-1980s. In a study of U.S. population, a positive J-shaped association was found between BMI and mortality, and based on that finding, a BMI of $25-29.9 \mathrm{~kg} / \mathrm{m}^{2}$ was classified as low risk, $30-39.9 \mathrm{~kg} / \mathrm{m}^{2}$ as moderate risk, and $\geq 40 \mathrm{~kg} / \mathrm{m}^{2}$ as high risk. ${ }^{6}$ Based on these results, the definition of obesity in Western countries including the United States has categorized a BMI of $25-29.9 \mathrm{~kg} / \mathrm{m}^{2}$ as overweight, $\geq 30 \mathrm{~kg} / \mathrm{m}^{2}$ as obesity; $30-34.9 \mathrm{~kg} / \mathrm{m}^{2}$ as class I obesity, $35-39.9 \mathrm{~kg} / \mathrm{m}^{2}$ as class II obesity, and $\geq 40 \mathrm{~kg} / \mathrm{m}^{2}$ as class III obesity.

However, in several studies on the elderly ${ }^{7}$ and patients with congestive heart failure ${ }^{8}$, chronic kidney disease ${ }^{9}$, and lung cancer ${ }^{10}$, being overweight was reported as potentially healthier than normal or low weight. Obesity may be protective and associated with greater survival, the so-called "obesity paradox," suggesting diverse associations between obesity and health risks. ${ }^{7-10}$ This concept of obesity paradox leads to confusion even in the general population regarding the criteria for ideal body weight.

\section{Factors influencing the relationship between BMI and mortality}

When interpreting the results of cohort studies regarding the association between BMI as an independent variable and mortality as the dependent variable, characteristics such as age, comorbidity, follow-up period, cause of death, and moderators or mediators, should be considered because they affect the study results.

\section{Age effects}

The age of subjects in the study cohort can affect the results. In a meta-analysis of 239 prospective studies across four continents, the relationship between BMI and all-cause mortality was explored. Reportedly, the J-shaped association changed into the gentle Ushaped association as age increased. ${ }^{11}$ The nadir of BMI regarding mortality risk depended on age and increased in older age groups; the nadir of BMI was $22 \mathrm{~kg} / \mathrm{m}^{2}$ for baseline age of 35-49 years, 23 $\mathrm{kg} / \mathrm{m}^{2}$ for baseline age of $50-69$ years, and $24 \mathrm{~kg} / \mathrm{m}^{2}$ for baseline age of $70-89$ years. ${ }^{11}$

Similarly, in a cohort study of non-smoking Koreans, the risk of mortality associated with cardiovascular disease (CVD) was reported to be greater in younger than in older men, even at the same BMI level. ${ }^{12}$ These results indicate that older individuals who remained healthy appeared to have lower risk of mortality because younger individuals who were at a higher risk due to obesity already died. Regarding this issue, in a previous study, the mortality rate based on BMI showed curvilinear pattern in younger age and $\mathrm{J}$-shaped and U-shaped associations with increasing age, and near reverse J-shaped association in older age subjects. ${ }^{13}$ Based on these findings, determining a higher optimal BMI cut-off level for olderage individuals should be considered. ${ }^{13}$

\section{Comorbidity and follow-up period}

A study cohort of 18,860 working men 40-69 years of age including a subcohort of 7,865 healthy men showed a J-shaped association between BMI and all-cause mortality, and a curvilinear relationship of BMI with CVD and coronary heart disease mortality after a 35-year follow-up. ${ }^{14}$ However, in most of studies showing 
the obesity paradox, subjects tended to have severe comorbidities and were older with a shorter lifespan ${ }^{7-10,15}$; therefore, mortality as an outcome variable in these studies may be easily assessed even if the observation period is relatively short. Thus, findings from these studies cannot be applied to the general population. BMI increased mortality risk with a J-shaped association in the general population, while BMI showed a reversed pattern in patients with advanced chronic kidney disease; increased BMI was associated with decreased mortality risk and increased survival. ${ }^{16}$ Plausible mechanisms of obesity paradox include that obese individuals with excessive fat mass have enough metabolic reserve to survive for the remainder of their life. ${ }^{17}$ Fat storage might be protective and have beneficial effects in some individuals exposed to acute insults or chronic wasting, resources that subjects with low-normal BMI do not have. ${ }^{18}$

\section{Cause of death}

A study of more than one million individuals in the Asian population investigating the association between BMI and risk of death showed greater risk of death associated with a high BMI was observed among East Asians but not among Indians and Bangladeshis. ${ }^{19}$ This result indicates that even among Asians, the characteristics of Indians and Bangladeshis are quite different from East Asians. BMI showed U-shaped associations with CVD mortality or cancer mortality in the East Asian population, while the association with BMI and CVD mortality was a flat pattern; cancer mortality significantly decreased as BMI increased among Indians and Bangladeshis. This indicates that study findings may be different based on the outcome measures and major causes of death may affect the associations between $\mathrm{BMI}$ and mortality in a study population.

\section{Moderators}

Moderating factors that affect outcome variables similar to the predictor should be addressed. For example, smoking acts as a moderator in the association between obesity and death. In a study of participants in Swiss MONICA (MONItoring of trends and determinants in CArdiovascular disease) study with mean follow-up duration of 18.6 years, non-smokers showed a J-shaped association between BMI and mortality and the lowest mortality risk was associated with a BMI value of $20.0-22.4 \mathrm{~kg} / \mathrm{m}^{2}$. However, a U-shaped association between BMI and mortality was observed and a BMI value of $25.0-27.4 \mathrm{~kg} / \mathrm{m}^{2}$ was associated with the lowest risk of mortality in smokers. ${ }^{20}$ Therefore, the heterogeneity of a study population based on moderators may distort the results.

\section{Mediators}

Mediators may influence outcome variables directly as well as indirectly. For example, obesity may directly affect mortality, and obesity-induced metabolic comorbidities such as hypertension, diabetes mellitus (DM), and CVD may affect the risk of mortality. A Korean study explored attributable fractions of metabolic risk factors such as blood pressure, fasting glucose, total cholesterol, and $\mathrm{BMI}$ and their contribution to the risk of CVD and all-cause death. The attributable fractions for the risk of CVD death and all-cause death were 0.72 and 0.48 for blood pressure, 0.57 and 0.58 for fasting glucose, and 0.43 and 0.16 for total cholesterol, respectively; however, the values were 0.18 and -0.07 for BMI, respectively, indicating that attributable fractions of BMI for CVD and all-cause mortality were lower than other metabolic risk factors. ${ }^{21}$ These findings indicate that mediators have a critical role in the association between BMI and mortality. Furthermore, in a previous study among U.S. men, BMI was negatively correlated with the risk of mortality. ${ }^{22}$ Although BMI is generally used as an obesity index when exploring the association between obesity and risk of mortality in various populations, whether BMI is a reliable adiposity parameter that reflects health risk is questionable. In a previous study, BMI correlated better with fat-free mass $(\mathrm{r}=0.836)$ than fat mass $(\mathrm{r}=0.736) .{ }^{22}$

\section{Comparison of two representative Korean cohort studies}

Two Korean cohort studies that used the national health examination database of South Korean National Health Insurance System were published within an approximate 10-year interval. The lowest risk of mortality was associated with a BMI of $23-24.9 \mathrm{~kg} / \mathrm{m}^{2}$ in the 2006 study by Jee et al. ${ }^{23}$ and a BMI of $25-26.4 \mathrm{~kg} / \mathrm{m}^{2}$ in the 2015 study by Kim et al. ${ }^{24}$ The different findings between the two studies were attributed to changes in the characteristics of study subjects and mortality rate caused by time variations, even within the same ethnicity (Table 2).

Although sex proportion and mean age were similar between the 
Table 2. Comparison of two Korean national cohort studies conducted to investigate the relationship between $\mathrm{BMl}$ and mortality

\begin{tabular}{lcc}
\hline \multirow{2}{*}{ Variable } & \multicolumn{2}{c}{ Author (year) } \\
\cline { 2 - 3 } & Jee et al. $(2006)^{23}$ & Kim et al. $(2015)^{24}$ \\
\hline BMl for the lowest mortality $\left(\mathrm{kg} / \mathrm{m}^{2}\right)$ & $23-24.9$ & $25-26.4$ \\
Proportion of men (\%) & 63.5 & 61.1 \\
Mean age (yr) & 47.2 & 47.1 \\
Baseline dataset & NHIS 1992-1994 & NHIS 2003-2004 \\
Cohort sample & Office worker/teacher & Community participant \\
No. of analyzed samples & $1,213,829$ & 153,484 \\
Follow-up (yr) & 12 & 7.9 \\
No. of deaths (\%) & $82,342(6.7)$ & $3,937(2.5)$ \\
Death from cancer (\%), men/women* & $38 / 28$ & $32 / 30$ \\
Death from CVD (\%), men/women & $18 / 25$ & $13 / 16$ \\
\hline
\end{tabular}

*Proportion of death from cancer or CVD among total deaths.

BMI, body mass index; NHIS, National Health Insurance System; CVD, cardiovascular disease.

two studies, differences in the socioeconomic characteristics may exist because the study populations consisted of office workers and teachers in the 2006 study $^{23}$, and subjects participating in community health examinations in the 2015 study. ${ }^{24}$ Other factors affecting the results were mortality rate and cause of death. The all-cause mortality rate decreased from $6.7 \%$ in the 2006 study with a followup duration of 12 years to $2.5 \%$ in the 2015 study with a follow-up duration of approximately 8 years. The 2015 study may have included more elderly individuals, accounting for approximately a 5 -year increase in lifetime expectancy over the past 10 years among Koreans. $^{25}$

Mortality rate from cancers was not significantly different between the two studies; $33 \%$ in the 2006 study $^{23}$ (38\% in men and $28 \%$ in women) and $31 \%$ in the 2015 study $^{24}$ (32\% in men and $30 \%$ in women). The mortality rate from CVD significantly decreased from $21.5 \%$ in the 2006 study ( $18 \%$ in men and $25 \%$ in women) to $14.1 \%$ in the 2015 study (13\% in men and $16 \%$ in women). A recent statistical report showed that mortality from stroke in Korea has decreased $45.8 \%$ from 89.3 per 100,000 in 2000 to 53.2 in $2016^{26}$, possibly due to easily accessible medical treatment and developments in medical technology. The 2015 study showed CVD mortality was the lowest in individuals with a BMI of $28-29.9 \mathrm{~kg} / \mathrm{m}^{2}$; this group was initially considered to be at higher risk of CVD, but was managed strictly by available treatment. The recent advancements in medical technology maximize the effects of treatment and extend the lifetime expectancy even in high-risk groups, and could act as a critical bias in the association between BMI (independent variable) and mortality (outcome variable).

\section{Systematic review and meta-analysis of BMI and mortality}

A recent systematic review and meta-analysis of 230 cohort studies with 3.74 million participants showed that overweight and obesity are associated with increased risk of all-cause mortality and the nadir of the curve was observed at a BMI of $22-23 \mathrm{~kg} / \mathrm{m}^{2}$ among healthy never-smokers, and a BMI of $20-22 \mathrm{~kg} / \mathrm{m}^{2}$ with longer follow-ups to reduce confounding by prediagnostic weight loss. ${ }^{27}$ The past U.S. data for determining the obesity criteria also showed a BMI value of $21-22 \mathrm{~kg} / \mathrm{m}^{2}$ was associated with the lowest mortality; however, the BMI criteria for health risk stratification were arbitrarily defined as $25-30 \mathrm{~kg} / \mathrm{m}^{2}, 30-40 \mathrm{~kg} / \mathrm{m}^{2}$, and $\geq 40 \mathrm{~kg} / \mathrm{m}^{2}$ for low, moderate, and high risk, respectively. Considering the average BMI is $27 \mathrm{~kg} / \mathrm{m}^{2}$ in the U.S. population, a BMI $\geq 30 \mathrm{~kg} / \mathrm{m}^{2}$ could be the optimal criteria for obesity in that population. ${ }^{7}$

\section{DATA BASED ON RELATIONSHIP BETWEEN BMI AND MORBIDITY}

\section{Reason for the establishment of obesity criteria based on} the relationship between BMI and morbidity

The concept of obesity as impairing health status due to excessive or abnormal fat accumulation raises concern whether it is reasonable to set BMI composed of a combination of fat mass and fatfree mass as independent variable, and mortality with combined intrinsic and extrinsic causes as outcome variable. Moreover, highly developed medical standards and accessible health systems may play important roles in improving mortality rates in modern society. Therefore, determining the obesity criteria only from investigating the association between BMI and mortality may be unreasonable. Generally, criteria for most chronic diseases are defined by the cut-off points determined to increased health risk in the next stage. For example, the cut-off value of fasting glucose for the diagnosis of DM was defined by the level related to the development of complications from DM. ${ }^{28}$ Because obesity is an intractable chronic disease requiring long-term management, defining the diagnostic 
criteria for obesity and overweight should be based on evidence in terms of the association between BMI and obesity-related comorbidities rather than mortality.

\section{Findings in recent cohort studies of Europeans and} Koreans

A recent study of approximately 300,000 Europeans examined the associations between different adiposity measures and incidence of CVD and showed the nadir of BMI for the lowest risk of incident CVD events was $22-23 \mathrm{~kg} / \mathrm{m}^{2} .{ }^{29}$ Based on the recent data compiled by the KSSO with Korean National Health Insurance Corporation, hazard ratio (HR) of type 2 DM increased 2, 3, and 6 times in individuals with BMIs of 23-24.9, 25-29.9, and $\geq 30 \mathrm{~kg} / \mathrm{m}^{2}$, respectively, compared with those with a BMI of $18.5-22.9 \mathrm{~kg} / \mathrm{m}^{2}$ without abdominal obesity. HR of hypertension and dyslipidemia increased approximately 1.5, 2, and 2.5-3.5 times, respectively, indicating a BMI of $23 \mathrm{~kg} / \mathrm{m}^{2}$ was associated with increased risk. ${ }^{30}$ These findings are compatible with the 2000 Asia-Pacific guideline which defined a BMI of $23-24.9 \mathrm{~kg} / \mathrm{m}^{2}$ as overweight and BMI of $25-29.9 \mathrm{~kg} / \mathrm{m}^{2}$ and $\geq 30 \mathrm{~kg} / \mathrm{m}^{2}$ as class I obesity and class II obesity, respectively, based on the risk of comorbidities. ${ }^{31}$

\section{Comparison of comorbidity prevalence in Caucasian and Asian populations at given BMI levels}

In the data from the 1999-2000 National Health and Nutrition Examination Survey in the United States, the average BMI was $28.0 \mathrm{~kg} / \mathrm{m}^{2}$ and prevalence of DM was $4.0 \%, 6.3 \%$, and $14.0 \%$ in subjects with a BMI $<25,25-29.9, \geq 30 \mathrm{~kg} / \mathrm{m}^{2}$, respectively. ${ }^{32}$ We found the prevalence of DM was $9.6 \%, 13.1 \%$, and $21.8 \%$ in men and $5.8 \%, 16.4 \%$, and $19.3 \%$ in women in subjects with a BMI $<25,25-29.9$, and $\geq 30 \mathrm{~kg} / \mathrm{m}^{2}$, respectively, based on data analysis from the 2001 Korea National Health and Nutrition Examination Survey. Although mean BMI levels were $23.7 \mathrm{~kg} / \mathrm{m}^{2}$ in men and $23.3 \mathrm{~kg} / \mathrm{m}^{2}$ in women among Koreans, the prevalence of DM for the same BMI levels was much higher in the Korean than in the U.S. population. The prevalence of hypertension was $10.5 \%$, $14.9 \%$, and $23.7 \%$ in U.S. adults ${ }^{32}$, and $23.7 \%, 37.0 \%$, and $35.9 \%$ in men and $13.8 \%, 36.8 \%$, and $48.7 \%$ in women, respectively, among Koreans. The prevalence of hypertension was also higher in Koreans than in the U.S. adults, even within the same BMI levels (Fig.

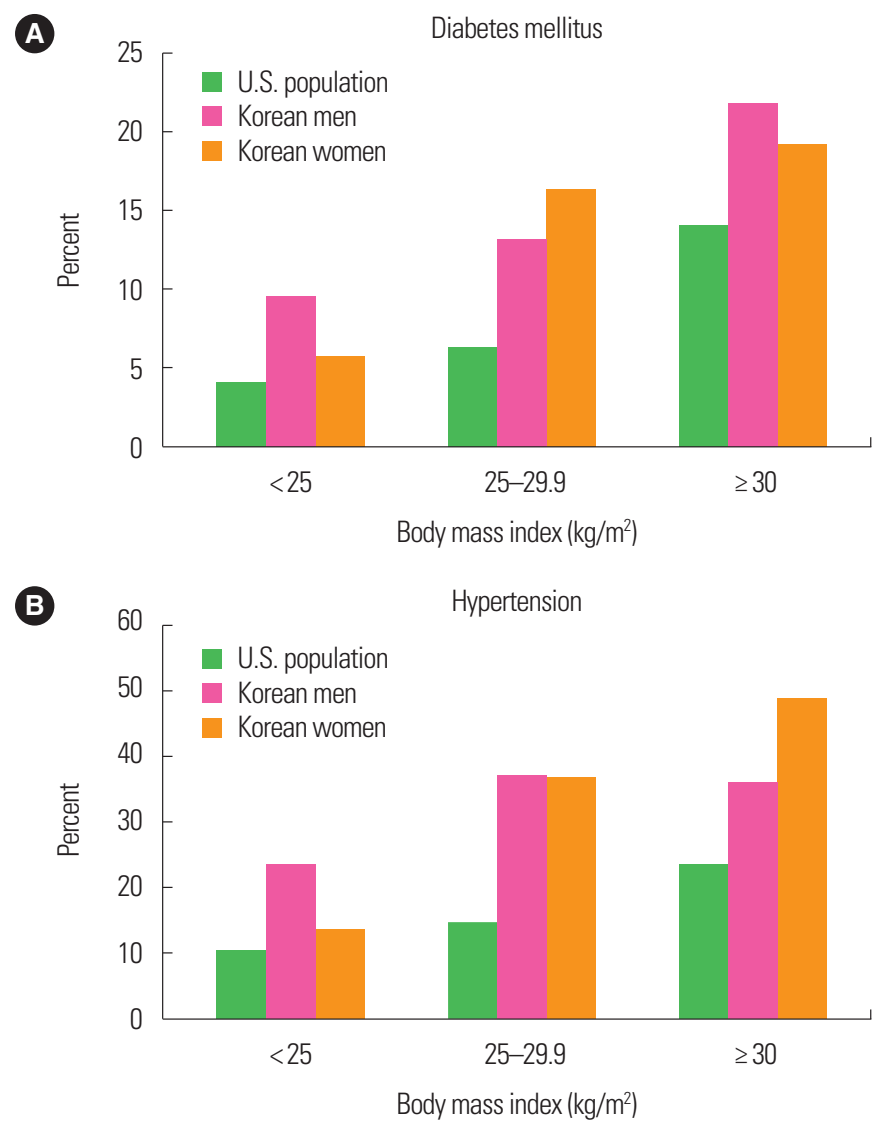

Figure 1. Comparison of diabetes mellitus $(\mathrm{A})$ and hypertension $(\mathrm{B})$ prevalence based on body mass index levels from the 1999-2000 National Health and Nutrition Examination Survey sample of U.S. subjects ${ }^{32}$ and 2001 Korea National Health and Nutrition Examination Survey sample of Korean subjects.

1). In accordance with these findings, a similar study of Caucasian and Chinese subjects showed the prevalence of DM, dyslipidemia, hypertension, and metabolic syndrome was higher in Chinese than Caucasians based on the same BMI. ${ }^{33}$

\section{Obesity criteria for the Asian populations}

The Japan Society for the Study of Obesity in 2011 emphasized the importance of obesity, defining BMI $\geq 25.0 \mathrm{~kg} / \mathrm{m}^{2}$ as "obesity disease. ${ }^{34}$ A recent study showed that a BMI of $22-23 \mathrm{~kg} / \mathrm{m}^{2}$ and $25-26 \mathrm{~kg} / \mathrm{m}^{2}$ in Chinese subjects were criteria for overweight and obesity, respectively, comparable to BMIs of $25 \mathrm{~kg} / \mathrm{m}^{2}$ and $30 \mathrm{~kg} / \mathrm{m}^{2}$ in Western populations. ${ }^{33}$ In the 2018 guideline for the management of obesity by the KSSO, a BMI of $23-24.9 \mathrm{~kg} / \mathrm{m}^{2}$ was defined as overweight (pre-obese) and $\geq 25 \mathrm{~kg} / \mathrm{m}^{2}$ as obesity in Korean adults based on data analysis of a large, nationally representative cohort because the risks of obesity-related comorbidities appeared to be 
higher among Asians than Caucasians, even with the same BMI values. Asians tend to have a smaller body size than Caucasians, probably due to limited expansion of adipose tissue in the body, thus, accumulated adipose tissue may be easily transformed pathologically. Limited expansion of adipose tissue is more likely to result in comorbidities with chronic inflammation. ${ }^{35}$

Based on the American Association of Clinical Endocrinologists/ American College of Endocrinology algorithm for the medical care of patients with obesity, U.S. populations with BMI $\geq 25 \mathrm{~kg} / \mathrm{m}^{2}$

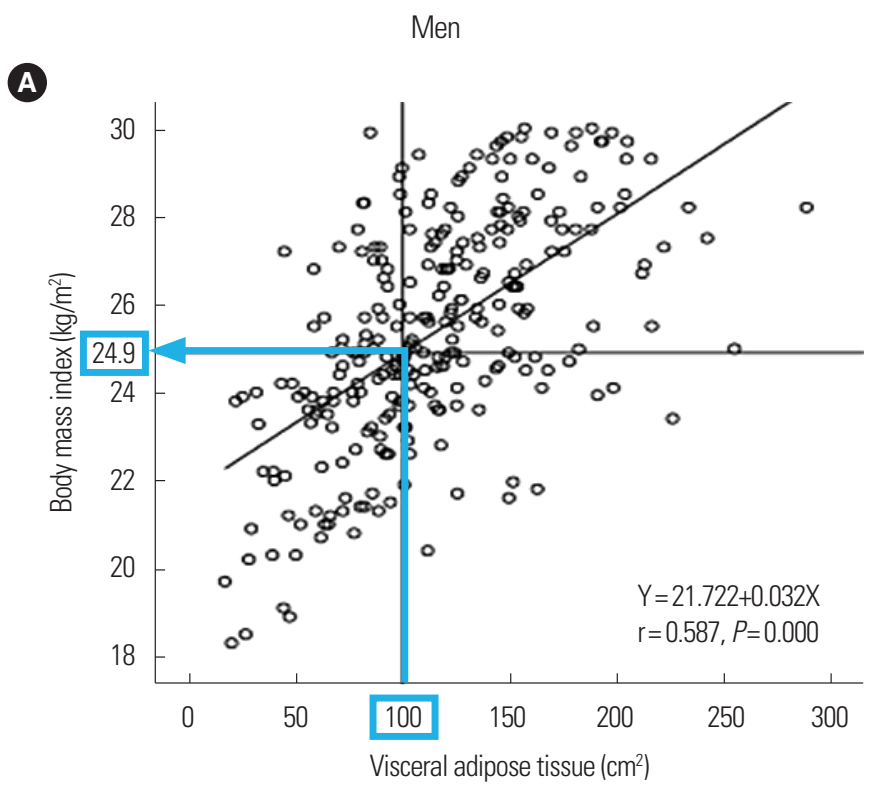

C

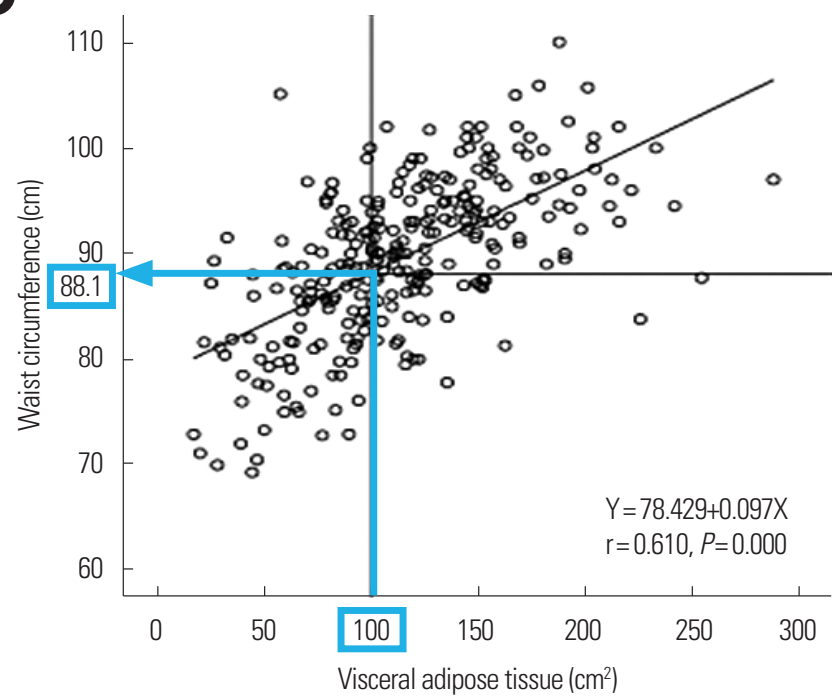

and some ethnicities with $\mathrm{BMI} \geq 23 \mathrm{~kg} / \mathrm{m}^{2}$ from annual BMI measurement are considered high-risk groups. ${ }^{36}$ American Diabetes Association guideline also states that Asians are a high-risk group, thus, Asian individuals with a BMI $\geq 23 \mathrm{~kg} / \mathrm{m}^{2}$, even if asymptomatic, should be screened for diabetes or prediabetes. The recommendations were based on the data analysis on incident diabetes in several prospective cohort studies in Asian American populations ${ }^{37}$, which is concordant with that Asians with a BMI $\geq 23 \mathrm{~kg} / \mathrm{m}^{2}$ are at the same risk level as Caucasians with a BMI $\geq 25 \mathrm{~kg} / \mathrm{m}^{2}{ }^{28}$

B

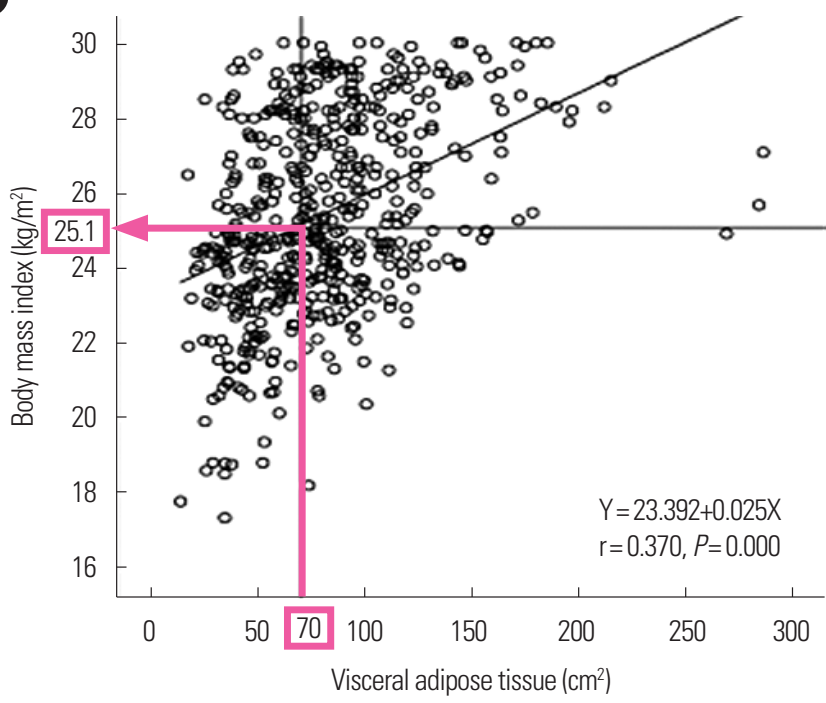

(D)

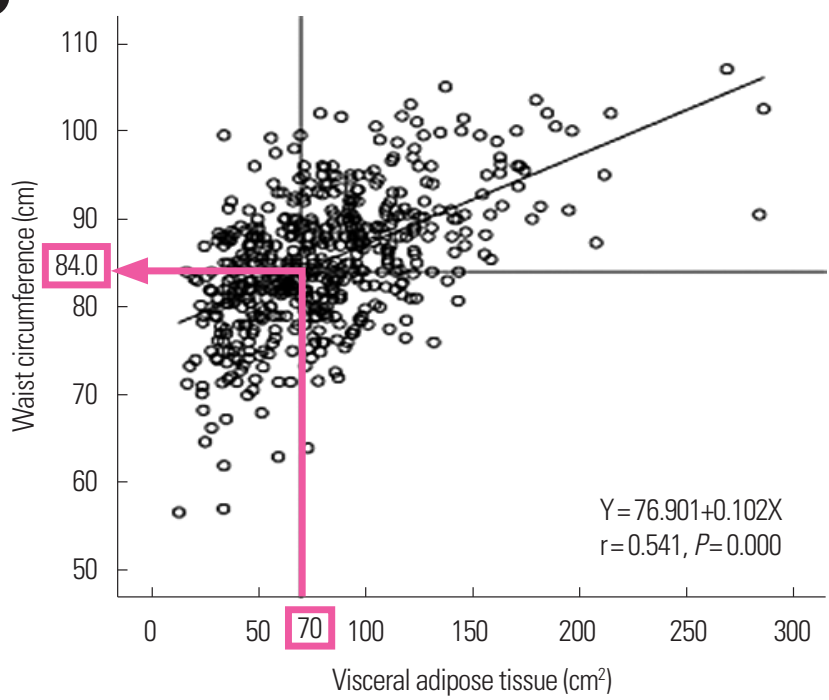

Figure 2. Body mass index (A, B) and waist circumference (C, D) cut-offs values corresponding to visceral adipose tissue for the prediction of obesity-related comorbidities in Korean men $\left(100 \mathrm{~cm}^{2}\right)$ and women $\left(70 \mathrm{~cm}^{2}\right)$. Adapted from Han et al. Diabet Med 2008;25:106-10, with permission of John Wiley and Sons. ${ }^{44}$ 


\section{CRITERIA FOR ABDOMINAL OBESITY}

\section{Criteria for abdominal obesity in Caucasians and Koreans}

Data used to establish the WC cut-offs for abdominal obesity in Caucasians showed that values determined from calculating the corresponding WC levels for were $25 \mathrm{~kg} / \mathrm{m}^{2}$ and $30 \mathrm{~kg} / \mathrm{m}^{2}$ of $\mathrm{BMI}^{38}$, respectively. From the assessment for increased cardiovascular risks by stage, WC cut-offs were defined $94 \mathrm{~cm}$ and $101 \mathrm{~cm}$ in men and $80 \mathrm{~cm}$ and $88 \mathrm{~cm}$ in women, respectively. ${ }^{39}$ The European Prospective Investigation into Cancer and Nutrition study showed positive linear associations of WC with mortality ${ }^{40}$ and morbidity ${ }^{29}$ after adjusting for BMI, indicating WC is a measurement of adiposity that better reflects health risk. In 2005, KSSO established the ethnicity-specific criteria for abdominal obesity in Koreans. WC appeared to increase cardiometabolic risk at $90 \mathrm{~cm}$ in men and $85 \mathrm{~cm}$ in women, and thus were made reference values for abdominal obesity in Korean adults. ${ }^{41}$ Similarly, studies in Japanese and Chinese populations showed the cut-offs of $90 \mathrm{~cm}$ in men and $85 \mathrm{~cm}$ in women are appropriate for diagnosing abdominal obesity.

\section{Visceral adipose tissue as a predictor of obesity-related comorbidities}

Abdominal obesity is important because it increases the health risks due to the accumulation of visceral fat. In Koreans, visceral fat areas $>100 \mathrm{~cm}^{2}$ in men and $>70 \mathrm{~cm}^{2}$ in women measured using abdominal fat computed tomography were apparently associated with increased cardiometabolic risk. ${ }^{44} \mathrm{~A}$ study of Japanese subjects showed nearly the same abdominal visceral fat area values in men and women, respectively, which is in accordance with our findings. ${ }^{42}$ Among Koreans, BMI values and WC levels corresponding to visceral fat areas of $100 \mathrm{~cm}^{2}$ in men and $70 \mathrm{~cm}^{2}$ in women were $24.9 \mathrm{~kg} / \mathrm{m}^{2}$ and $25.1 \mathrm{~kg} / \mathrm{m}^{2}$, and $88.1 \mathrm{~cm}$ and $84.0 \mathrm{~cm}$, respectively (Fig. 2). ${ }^{44}$ These findings showed consistency of the cut-off values for BMI, WC, and visceral fat area in predicting obesity-related comorbidities and are used as the criteria for obesity and abdominal obesity in Korean adults.

\section{CONCLUSION}

In this review, we examined the validity of the current criteria for obesity and abdominal obesity in Korean adults based on the evidence regarding the associations of obesity index with mortality and morbidity. The BMI cut-off values of $25 \mathrm{~kg} / \mathrm{m}^{2}$ for obesity and $23 \mathrm{~kg} / \mathrm{m}^{2}$ for overweight, and WC cut-off values of $\geq 90 \mathrm{~cm}$ in men and $\geq 85 \mathrm{~cm}$ in women for abdominal obesity are reasonable and valid when considering the health risk characteristics of Korean adults. As the elderly population increases with a longer lifespan, the optimal cut-off values for obesity and abdominal obesity may require adjustment after accounting for age and health status. In addition, developing more valid and reliable obesity indicators that can better reflect morbidity in obesity-related disorders and future mortality is needed.

\section{CONFLICTS OF INTEREST}

The authors declare no conflict of interest.

\section{ACKNOWLEDGMENTS}

This research was supported by the Basic Science Research Program through the National Research Foundation of Korea (NRF No. 2017030666) funded by the Ministry of Education, Science and Technology, Republic of Korea.

\section{REFERENCES}

1. World Health Organization. Obesity and overweight [Internet]. Geneva: World Health Organization; 2018 [cited 2018 Sep 3]. Available from: http://www.who.int/news-room/fact-sheets/ detail/obesity-and-overweight

2. Medscape. Obesity to overtake smoking as leading cause of death [Internet]. New York, NY: Medscape; 2004 [cited 2018 Sep 3]. Available from: https://www.medscape.com/viewarticle/474966

3. OECD. Obesity update 2017. Paris: OECD; 2017.

4. World Health Organization. Obesity preventing and managing the global epidemic: report of a WHO consultation on obesity. Geneva: World Health Organization; 1997.

5. Korean Society for the Study of Obesity. Guideline for the management of obesity 2018. Seoul: Korean Society for the 
Study of Obesity; 2018.

6. Bray GA. Complications of obesity. Ann Intern Med 1985; 103(6 Pt 2):1052-62.

7. Kvamme JM, Holmen J, Wilsgaard T, Florholmen J, Midthjell $\mathrm{K}$, Jacobsen BK. Body mass index and mortality in elderly men and women: the Tromso and HUNT studies. J Epidemiol Community Health 2012;66:611-7.

8. Kalantar-Zadeh K, Block G, Horwich T, Fonarow GC. Reverse epidemiology of conventional cardiovascular risk factors in patients with chronic heart failure. J Am Coll Cardiol 2004;43: $1439-44$.

9. Kalantar-Zadeh K, Block G, Humphreys MH, Kopple JD. Reverse epidemiology of cardiovascular risk factors in maintenance dialysis patients. Kidney Int 2003;63:793-808.

10.Zhang X, Liu Y, Shao H, Zheng X. Obesity paradox in lung cancer prognosis: evolving biological insights and clinical implications. J Thorac Oncol 2017;12:1478-88.

11. Global BMI Mortality Collaboration, Di Angelantonio E, Bhupathiraju SN, Wormser D, Gao P, Kaptoge S, et al. Body-mass index and all-cause mortality: individual-participant-data metaanalysis of 239 prospective studies in four continents. Lancet 2016;388:776-86.

12. Park HS, Song YM, Cho SI. Obesity has a greater impact on cardiovascular mortality in younger men than in older men among non-smoking Koreans. Int J Epidemiol 2006;35:181-7.

13. Childers DK, Allison DB. The 'obesity paradox': a parsimonious explanation for relations among obesity, mortality rate and aging? Int J Obes (Lond) 2010;34:1231-8.

14. Kivimäki M, Ferrie JE, Batty GD, Davey Smith G, Elovainio M, Marmot MG, et al. Optimal form of operationalizing BMI in relation to all-cause and cause-specific mortality: the original Whitehall study. Obesity (Silver Spring) 2008;16:1926-32.

15. Vecchié A, Dallegri F, Carbone F, Bonaventura A, Liberale L, Portincasa $\mathrm{P}$, et al. Obesity phenotypes and their paradoxical association with cardiovascular diseases. Eur J Intern Med 2018; 48:6-17.

16. Kalantar-Zadeh K, Rhee CM, Chou J, Ahmadi SF, Park J, Chen $\mathrm{JL}$, et al. The obesity paradox in kidney disease: how to reconcile it with obesity management. Kidney Int Rep 2017;2:27181.
17. Dorner TE, Rieder A. Obesity paradox in elderly patients with cardiovascular diseases. Int J Cardiol 2012;155:56-65.

18. Lopez-Jimenez F. Speakable and unspeakable facts about BMI and mortality. Lancet 2009;373:1055-6.

19. Zheng W, McLerran DF, Rolland B, Zhang X, Inoue M, Matsuo $\mathrm{K}$, et al. Association between body-mass index and risk of death in more than 1 million Asians. N Engl J Med 2011;364: 719-29.

20. Faeh D, Braun J, Tarnutzer S, Bopp M. Obesity but not overweight is associated with increased mortality risk. Eur J Epidemiol 2011;26:647-55.

21. Park HS, Cho SI, Song YM, Sung J. Multiple metabolic risk factors and total and cardiovascular mortality in men with low prevalence of obesity. Atherosclerosis 2006;187:123-30.

22. Allison DB, Zhu SK, Plankey M, Faith MS, Heo M. Differential associations of body mass index and adiposity with allcause mortality among men in the first and second National Health and Nutrition Examination Surveys (NHANES I and NHANES II) follow-up studies. Int J Obes Relat Metab Disord 2002;26:410-6.

23.Jee SH, Sull JW, Park J, Lee SY, Ohrr H, Guallar E, et al. Bodymass index and mortality in Korean men and women. N Engl J Med 2006;355:779-87.

24. Kim NH, Lee J, Kim TJ, Kim NH, Choi KM, Baik SH, et al. Body mass index and mortality in the general population and in subjects with chronic disease in Korea: a nationwide cohort study (2002-2010). PLoS One 2015;10:e0139924.

25. Statistics Korea. 2016 Life tables [Internet]. Daejeon: Statistics Korea; 2017 [cited 2018 Sep 5]. Available from: http://kostat. go.kr/portal/korea/kor_nw/2/2/7/index.board

26. Statistics Korea. 2016 Statistics for causes of death [Internet]. Daejeon: Statistics Korea; 2017 [cited 2018 Sep 5]. Available from: http://kostat.go.kr/portal/korea/kor_nw/2/6/2/index. board

27. Aune D, Sen A, Prasad M, Norat T, Janszky I, Tonstad S, et al. BMI and all cause mortality: systematic review and non-linear dose-response meta-analysis of 230 cohort studies with 3.74 million deaths among 30.3 million participants. BMJ 2016; 353:i2156.

28. American Diabetes Association. 2. Classification and diagnosis 
of diabetes: standards of medical care in diabetes-2018. Diabetes Care 2018;41(Suppl 1):S13-27.

29. Iliodromiti S, Celis-Morales CA, Lyall DM, Anderson J, Gray SR, Mackay DF, et al. The impact of confounding on the associations of different adiposity measures with the incidence of cardiovascular disease: a cohort study of 296535 adults of white European descent. Eur Heart J 2018;39:1514-20.

30. Korean Society for the Study of Obesity. 2017 Obesity fact sheet. Seoul: Korean Society for the Study of Obesity; 2017.

31. World Health Organization; Regional Office for the Western Pacific; International Diabetes Institute; International Association for the Study of Obesity; International Obesity Task Force. The Asia-Pacific perspective: redefining obesity and its treatment. Sydney: Health Communications Australia; 2000.

32. Gregg EW, Cheng YJ, Cadwell BL, Imperatore G, Williams DE, Flegal KM, et al. Secular trends in cardiovascular disease risk factors according to body mass index in US adults. JAMA 2005;293:1868-74.

33. He W, Li Q, Yang M, Jiao J, Ma X, Zhou Y, et al. Lower BMI cutoffs to define overweight and obesity in China. Obesity (Silver Spring) 2015;23:684-91.

34. Takahashi H, Mori M. Characteristics and significance of criteria for obesity disease in Japan 2011. Nihon Rinsho 2013;71: 257-61.

35. Sun K, Kusminski CM, Scherer PE. Adipose tissue remodeling and obesity. J Clin Invest 2011;121:2094-101.

36. American Association of Clinical Endocrinologists. AACE/ ACE algorithm for the medical care of patients with obesity [Internet]. Jacksonville, FL: American Association of Clinical
Endocrinologists; 2016 [cited 2018 Sep 3]. Available from: https://www.aace.com/files/guidelines/ObesityAlgorithm.pdf

37. Hsu WC, Araneta MR, Kanaya AM, Chiang JL, Fujimoto W. BMI cut points to identify at-risk Asian Americans for type 2 diabetes screening. Diabetes Care 2015;38:150-8.

38. Lean ME, Han TS, Morrison CE. Waist circumference as a measure for indicating need for weight management. BMJ 1995;311:158-61.

39. Han TS, van Leer EM, Seidell JC, Lean ME. Waist circumference action levels in the identification of cardiovascular risk factors: prevalence study in a random sample. BMJ 1995;311: 1401-5.

40. Pischon T, Boeing H, Hoffmann K, Bergmann M, Schulze $\mathrm{MB}$, Overvad K, et al. General and abdominal adiposity and risk of death in Europe. N Engl J Med 2008;359:2105-20.

41.Lee SY, Park HS, Kim DJ, Han JH, Kim SM, Cho GJ, et al. Appropriate waist circumference cutoff points for central obesity in Korean adults. Diabetes Res Clin Pract 2007;75:72-80.

42. Kashihara H, Lee JS, Kawakubo K, Tamura M, Akabayashi A. Criteria of waist circumference according to computed tomography-measured visceral fat area and the clustering of cardiovascular risk factors. Circ J 2009;73:1881-6.

43. Bao Y, Lu J, Wang C, Yang M, Li H, Zhang X, et al. Optimal waist circumference cutoffs for abdominal obesity in Chinese. Atherosclerosis 2008;201:378-84.

44. Han JH, Park HS, Kim SM, Lee SY, Kim DJ, Choi WH. Visceral adipose tissue as a predictor for metabolic risk factors in the Korean population. Diabet Med 2008;25:106-10. 